\title{
ANÁLISE ACERCA DA LIBERDADE INDIVIDUAL VERSUS A CONVIVÊNCIA FAMILIAR: COLISÃO DE DIREITOS E A TUTELA GERAL DOS DIREITOS DA PERSONALIDADE*
}

\author{
An analysis about individual freedom versus family life: \\ collision of rights and the general protection of personality \\ rights
}

Análisis sobre la libertad individual versus la vida familiar:
colisión de derechos y la tutela general de los derechos de la personalidad

Diego Fernandes Vieira
diego.vieira_180@hotmail.com

Carlos Alexandre Moraes ${ }^{b}$

camoraes.adv@hotmail.com

Fecha de recepción: 11 de enero de 2020 Fecha de revisión: 29 de enero de 2020 Fecha de aceptación: 16 de febrero de 2020

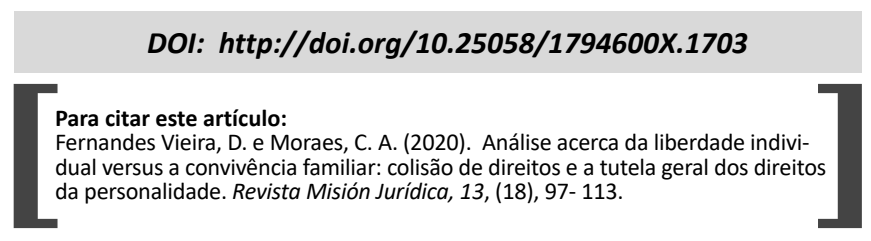

\section{RESUMO}

Este trabalho tem por objetivo analisar os direitos à liberdade individual e à convivência familiar, voltando-se para uma possível colisão de direitos diante do eventual não querer conviver do genitor para com a prole. A hipótese a ser enfrentada é a de se realmente existe uma colisão de direitos fundamentais ante a tutela geral dos direitos da personalidade e um limite dos limites. Para tanto, o presente estudo se valeu do método hipotético-dedutivo, fundamentado em revisão bibliográfica que, por meio do material coletado, intentou compreender os valores da Constituição Federal de 1988 e o seu caráter protetivo da criança e do adolescente. Conclui-se, portanto, que atualmente é inegável a relevância da convivência familiar para o desenvolvimento e o crescimento dos filhos. Logo, incumbe aos pais o dever jurídico de garantir e efetivar os direitos infanto-juvenis, não havendo discricionariedade neste âmbito. Assim, há uma simples colisão aparente de direitos e não

\footnotetext{
* Este artigo de revisão foi elaborado pelos autores no âmbito do Programa de Pós-Graduação em Ciências Jurídicas do Centro Universitário de Maringá (UniCesumar), na cidade de Maringá, Paraná, Brasil, no ano de 2019.

a. Mestrando no Programa de Pós-graduação em Ciências Jurídicas pelo Centro Universitário de Maringá -Unicesumar - Bolsista do Programa de Suporte à Pós-Graduação de Instituições de Ensino Particulares (PROSUP/CAPES); Graduado em Direito pelo Centro Universitário de Maringá (Unicesumar); Graduando em Administração pelo Centro Universitário Leonardo da Vinci (Uniasselvi); Integrante do Grupo de Pesquisa: "Reconhecimento e garantia dos direitos da personalidade".

b. Pós-Doutor em Direito pela Unicesumar, Doutor em Direito pela Fadisp e Doutor em Ciências da Educação pela Upap; Mestre em Ciências Jurídicas pela Unicesumar; Professor do Programa de Pós-Graduação Stricto Sensu - Mestrado da Unicesumar; Professor dos Cursos de Graduação em Direito da UniCesumar e da Univel; Coordenador e Professor dos Cursos de Pós-Graduação Lato Sensu em Direito da Faculdade Dom Bosco Maringá e Instituto Carlos Alexandre Moraes - ICAM; Avaliador dos Cursos de Direito do Instituto Nacional de Estudos e Pesquisas Educacionais (INEP/MEC); Palestrante; Autor de livros e Advogado.
} 
uma colisão real, em razão do direito à liberdade individual não abarcar esta situação fática e jurídica.

\section{PALAVRAS-CHAVES}

Constitucionalização; colisão aparente; direitos da personalidade; direitos fundamentais.

\begin{abstract}
This paper aims to analyze the rights to individual freedom and family companionship, despite a possible collision of rights if parents desire not to have contact with the child. The hypothesis to be studied is if there really is a collision of fundamental rights against the general protection of personality rights and the limits between those rights. To this end, the present study used the hypothetical-deductive method, based on a bibliographical review that, through the material collected, intended to understand the values of the Federal Constitution of 1988 and its protection of children and adolescents. Therefore, it is concluded that nowadays the relevance of family companionship for the development and growth of the child is undeniable. Therefore, parents have a legal duty to guarantee and enforce children's rights, so there is no dispute in this area. Thus, there is just a simple apparent collision of rights and not a real collision, because the right to individual freedom does not embrace this factual and legal situation.
\end{abstract}

\section{KEY WORDS}

Constitutionalization; apparent collision; fundamental rights of children, personality rights; Fundamental Rights.

\section{RESUMEN}

Este artículo tiene como objetivo analizar los derechos a la libertad individual y la convivencia familiar, confrontando una posible colisión de derechos frente a la eventual falta de voluntad del progenitor de convivir con sus hijos. La hipótesis a confrontar es si realmente existe una colisión de derechos fundamentales frente a la protección general de los derechos de la personalidad y un límite entre ellos. Para este fin, el presente estudio utilizó el método hipotético-deductivo, basado en una revisión bibliográfica que, por medio del material analizado, llevó a entender los valores de la Constitución Federal de 1988 y su carácter protector de los niños y adolescentes. Se concluye que, actualmente, es innegabe la relevancia de la convivencia familiar para el desarrollo y crecimiento de los niños. Por lo tanto, corresponde a los padres el deber legal de garantizar y hacer cumplir los derechos del niño y el adolescente, sin que haya discrecionalidad en este ámbito. De allí que solo existe una simple colisión aparente de derechos y no una colisión real, porque el derecho a la libertad individual no abarca esta situación fáctica y jurídica.

\section{PALABRAS CLAVES}

Constitucionalización; aparente colisión; derechos fundamentales de los niños; derechos de la personalidad; derechos fundamentales.

\section{INTRODUÇÃO}

0 movimento de constitucionalização do Direito Civil brasileiro bem como o da proteção dos direitos da personalidade, acarretou uma mudança de paradigma e na valoração dos bens jurídicos, colocando em voga o princípio da unidade da Constituição Federal de 1988 e de todo o ordenamento jurídico nacional. Nessa perspectiva, os direitos fundamentais e os princípios constitucionais aperfeiçoam e norteiam toda a legislação vigente e a vida em sociedade no Estado Democrático de Direito.

Os direitos fundamentais individuais e coletivos se perfazem muitas vezes em uma relação com o outro, e é nesse relacionamento social que ocorre a denominada "colisão de direitos/princípios". Para uma melhor compreensão da temática, neste trabalho os termos direitos fundamentais e princípios constitucionais serão tratados como sinônimos, visto que os conflitos que nascem em torno dos direitos fundamentais são idênticos aos conflitos relativos aos princípios.

Por este motivo, se faz necessária uma análise voltada para o Direito de Família, com foco na relação parental entre o genitor não guardião e a sua prole. Relação esta sine qua non para o desenvolvimento psicofísico do menor e para o próprio aperfeiçoamento do genitor como pessoa humana.

A preocupação com a criança e com o adolescente se encontra mais que evidente tanto 
socialmente como juridicamente, pois o bemestar infanto-juvenil é objeto universal de atenção, tanto da doutrina como da jurisprudência e, especialmente, do Direito Constitucional. Estabelecendo-se, assim, mais do que uma proteção legislada, mas uma solução de conflitos, de forma que se possa alcançar a concordância prática entre todos os direitos e princípios fixados e valorados.

Por se tratar de uma colisão tanto de princípios como de direitos fundamentais, a resposta mais evidente para o conflito entre a liberdade individual do genitor e o direito de convivência do filho, segundo a doutrina, seria a utilização técnica da ponderação de interesses e da proporcionalidade para a tomada de decisão. Mas será que realmente existe uma colisão de direitos fundamentais em casos envolvendo a relação parental? Além disso, é possível a prevalência de um direito/princípio em face do outro em certas situações fáticas?

Assim, frente a tais indagações, para a realização da presente pesquisa aplicou-se o método teórico, que se expressa pela revisão bibliográfica de obras, artigos científicos publicados em periódicos da área, bem como de documentos eletrônicos sobre a temática. Utilizou-se também o método de procedimento hipotético-dedutivo, partindo da premissa envolvendo o direito à liberdade e o direito de convivência familiar para assim traçar uma compressão sobre eles e de eventual colisão.

\section{METODOLOGIA}

A pesquisa em comento aborda dois direitos fundamentais em específico, quais sejam: o direito à liberdade individual do genitor e o direito à convivência familiar do filho menor, abordando tal controvérsia sob a perspectiva dos métodos hipotético-dedutivo, analítico crítico e bibliográfico, por meio dos estudos já realizados até a presente data, a fim de compreendê-los para o enfrentamento da hipótese sustentada. Assim, constitui o objetivo deste trabalho a verificação quanto à existência ou não de uma colisão de direitos fundamentais e se é necessária a aplicação do mecanismo da ponderação e da proporcionalidade.

\section{DA CLÁUSULA GERAL DE TUTELA DA PERSONALIDADE NA CONSTITUIÇÃOFEDERAL BRASILEIRA}

Com a promulgação da Constituição Federal de 1988 foram proclamados alguns princípios estruturantes e otimizantes do ordenamento jurídico e social, quais sejam: o princípio da igualdade, inserido no preâmbulo ${ }^{1}$ e no art. 5o, caput $^{2}$, e o princípio da dignidade da pessoa humana, alocado no inciso III, do art. 1.o da Constituição ${ }^{3}$. Referidos princípios podem ser entendidos como "a base e o substrato necessário à constituição dos demais direitos, tutelando a pessoa humana em toda a sua dimensão, uma vez que a mesma é portadora de dignidade e de igualdade, sob seu aspecto formal e material" (Szaniawski, 2005: 137). Desta forma, Cantali, de maneira pontual, aduz que:

A Constituição Federal de 1988 trouxe em seu corpo diversos valores e princípios dos quais se instaurou uma nova ordem jurídica que impôs um repensar de todo sistema, na medida em que o ser humano, diante da eleição da dignidade da pessoa humana como fundamento do próprio Estado Democrático de Direito, passou a ocupar o centro referencial do ordenamento $(2009, \mathrm{p} .84)$.

Assim, "têm-se entendido o caráter principiológico das normas que conferem direitos fundamentais" (Mastrodi, 2014, p.581) à medida que o seu conteúdo e objetivo são semelhantes, tanto dos direitos fundamentais como dos princípios constitucionais, visto que "a expressão direitos fundamentais do homem são situações jurídicas, objetivas e subjetivas, definidas no direito positivo, em prol da dignidade, igualdade e liberdade da pessoa" (Silva, 2005: 179).

1. Preâmbulo: "Nós, representantes do povo brasileiro, reunidos em Assembléia Nacional Constituinte para instituir um Estado Democrático, destinado a assegurar o exercício dos direitos sociais e individuais, a liberdade, a seguranca, o bem-estar, o desenvolvimento, a igualdade e a justiça como valores supremos de uma sociedade fraterna, pluralista e sem preconceitos, fundada na harmonia social e comprometida, na ordem interna $e$ internacional, com a solução pacífica das controvérsias, promulgamos, sob a proteção de Deus, a seguinte CONSTITUIÇÃO DA REPUBLICA FEDERATIVA DO BRASIL". (Brasil, 1988).

2. Art. 5o caput: "Todos são iguais perante a lei, sem distinção de qualquer natureza, garantindo-se aos brasileiros e aos estrangeiros residentes no País a inviolabilidade do direito a vida, à liberdade, à igualdade, à segurança e à propriedade, nos termos seguintes". (Brasil, 1988).

3. Art. 1ํ, inciso III: "a dignidade da pessoa humana".(Brasil, 1988). 
Por este motivo, Sarlet (2004: 110) sustenta que "os direitos fundamentais, ao menos de forma geral, podem ser considerados concretizações das exigências do princípio da dignidade da pessoa humana". A dignidade humana, voltada para o âmbito jurídico, funciona como uma forma de proteção da pessoa humana e tende a ser o limite, o início e o fim de qualquer questão que envolva o bem-estar individual e coletivo. Desta feita, Alexy entende que:

Direitos fundamentais são essencialmente direitos do homem transformados em direito positivo. Direitos do homem insistem em sua institucionalização. Assim, existe não somente um direito do homem à vida, senão também um direito do homem a isto, que exista um Estado que concretize tais direitos. A institucionalização inclui necessariamente justicialização (1999: 73).

O qualificativo "fundamentais" carrega consigo a compreensão de que se tratam de direitos sem os quais nenhuma pessoa conseguirá se desenvolver, se realizar, conviver e, até mesmo, sobreviver, já que são fundamentais, no sentido de que pertencem a todas as pessoas, e assim, devem não apenas ser reconhecidos, mas também garantidos de forma concreta.

Os direitos fundamentais podem ser traduzidos como os direitos sem os quais as pessoas não iriam se desenvolver, se realizar e viver de forma digna. São os direitos que vêm sendo conquistados de forma gradativa e histórica, e que devem ser assegurados para todas as pessoas, desde a infância até a velhice, e não somente para uma parcela da sociedade.

Ainda, Fachin (2006) compreende que esta visão principiológica da dignidade humana permeia todo o ordenamento jurídico e possui o objetivo de conceber um substrato axiológico para todos os outros princípios e direitos protetivos de bens não patrimoniais, como por exemplo, os direitos da personalidade.

Estes, segundo França (1996), poderiam ser traduzidos como "faculdades jurídicas cujo objeto são os diversos aspectos da própria pessoa do sujeito, bem assim as suas emanações e prolongamentos" (p. 1033). Assim, Gagliano e Pamplona Filho definem os direitos da personalidade como "aqueles que têm por objeto os atributos físicos, psíquicos e morais da pessoa em si e em suas projeções sociais" (2003: 144).

Na tentativa de abarcar toda a complexibilidade destes direitos, Tartuce (2018) observa que estes possuem como bem jurídico a ser tutelado exatamente o modo de ser dos humanos, em seu mais amplo sentido, abarcando os aspectos físicos, psíquicos, morais e intelectuais da pessoa, e que tem como finalidade de proteger e resguardar estes aspectos da personalidade, sendo titular destes direitos o ente considerado pessoa, seja ela física ou jurídica. Conforme Fermentão:

A pessoa, como ser capaz de manifestações interiores, necessita de proteção adequada que garanta a sua existência e o pleno desenvolvimento físico e moral da sua personalidade. Como os direitos de personalidade são essenciais para salvaguardar dignidade humana, privado deles, o homem não se desenvolve. A essencialidade dos direitos personalíssimos é a valoração destes na vida do ser humano. Se os direitos da personalidade são essenciais, logo, são necessários evitais para o desenvolvimento da pessoa humana. (2006: 264).

Os direitos da personalidade são mais do que simples direitos legislados, mas o reflexo do desenvolvimento social e jurídico do ordenamento brasileiro, vinculado exatamente à concepção de direitos humanos e fundamentais, ligados à pessoa e ao seu mais íntimo significado, desde a sua concepção até a morte. São direitos que resguardam a essência de cada ser humano, preservando a dignidade e, consequentemente, uma vida digna. "Direitos são a cristalização, em normas jurídicas, de valores ou interesses considerados importantes pela sociedade que os positivou" (Mastrodi, 2014: 580).

Como se pode verificar, "não há uma diferença substancial entre os direitos da personalidade e os direitos fundamentais. Simplesmente os diretos de personalidade são direitos fundamentais em sede de Direito Privado" (Cantali, 2009: 129), e também não há distinção voltada para o âmbito de aplicação destes, posto que o movimento de constitucionalização do Direito Privado fez com que a tutela jurídica da pessoa humana estivesse presente tanto no âmbito público como no privado, partindo-se de uma visão unitária do sistema jurídico (Tartuci, 2018). "Pode-se, inclusive, nomeá-los como direitos fundamentais da personalidade" (Cantali, 2009: 129). 
Por este motivo é que se sustenta a afirmação de que "o ordenamento jurídico brasileiro, no tocante à tutela da personalidade humana, adotou um sistema de proteção misto" (Szaniawski, 2005, p.137). 0 ordenamento brasileiro enuncia o sistema geral de proteção da personalidade (princípio da dignidade humana), ao lado de direitos especiais de personalidade, elencados na Constituição Federal e no Código Civil (arts. 11 ao 21).

Embora a Constituição não tenha inserido de forma explícita a tutela da personalidade humana, reconheceu-a por meio do princípio da dignidade da pessoa humana, que se perfaz como cláusula geral de proteção e de efetivação dos direitos de personalidade, garantindo a todos o desenvolvimento individual e coletivo.

A Constituição brasileira de 1988 somente seguiu uma tendência mundial, qual seja: a do reconhecimento de um direito geral de personalidade. Esta tutela é consagrada no artigo $1^{\text {o }}$ do texto constitucional, bem como em forma de tutela específica por meio do artigo 5‥ Assim, a dignidade da pessoa humana é tida como o ponto cardeal da proteção destes direitos em razão de que ela "por si só, traz todos os atributos inerentes à personalidade humana" (Cantali, 2009: 90).

Esta cláusula geral tende, exatamente, a abarcar não apenas as situações jurídicas expostas de forma taxativa, mas também a abranger as de desdobramento que a personalidade pode acarretar. Personalidade esta que é valor estruturante do sistema jurídico e que, no dizer de Perlingieri (2002: 155) constitui a "base de uma série aberta de situações existenciais, nas quais se traduz a sua incessante e mutável exigência de tutela".

Assim sendo, Tepedino, de forma clara e direita, observa que:

Com efeito, a escolha da dignidade da pessoa humana como fundamento da República, associada ao objetivo fundamental de erradicação da pobreza e da marginalização, e de redução das desigualdades sociais, juntamente com a previsão do $\S 2 .^{\circ}$ do art. 5. ${ }^{\circ}$, no sentido de não exclusão de quaisquer direitos e garantias, mesmo que não expressos, desde que decorrentes dos princípios adotados pelo texto maior, configuram uma verdadeira cláusula geral de tutela e promoção da pessoa humana, tomada como valor máximo pelo ordenamento (Tepedino, 2004: 50).

No ano de 2006, durante a IV Jornada de Direito Civil, foi aprovado o Enunciado no 274 do Conselho da Justiça Federal (CJF) em parceria com o Superior Tribunal de Justiça (ST)), que prevê, em sua ementa, que "os direitos da personalidade, regulados de maneira não exaustiva pelo Código Civil, são expressões da cláusula geral de tutela da pessoa humana, contida no art. 1.o III, da Constituição Federal". O que deixa claro a afirmação sustentada até o presente momento. Desta forma, é preciso que se supere, de forma definitiva, esta "concepção do Estado de Direito Formal, em que os direitos fundamentais somente ganham expressão regulados por lei, com o que se expõem ao esvaziamento de conteúdo pela atuação ou inação do legislador" (Mendes, Branco, 2015: 153).

Neste liame é que se evidencia que, diferentemente de outrora, quando os direitos fundamentais se perfaziam como resposta às reivindicações comuns a todas as pessoas. Atualmente o que se mostra é a necessidade de proteção de certas situações específicas em que certo grupo se encontra. Por este motivo é que algumas pessoas, por conta de suas especiais características, ou situação em que se encontram, tornam-se merecedoras de especial tutela.

Neste mesmo sentido, Anjos Filho pontua que:

A necessidade de assegurar os direitos específicos aos grupos vulneráveis em sentido estrito $e$ às minorias, diferentemente daqueles reconhecidos aos membros da sociedade dominante, encontrase implícita em todos os seus dispositivos que dizem respeito à necessidade de observância e concretização dos direitos humanos em geral, tidos como interdependentes e indivisíveis (Anjos Filho, 2013: 263).

A criança e o adolescente se encontram em uma situação em que carecem de especial tutela, tanto do Estado como dos entes privados, a fim deque sejam efetivados os seus direitos fundamentais e de personalidade. Ao se entender e reconhecer esta vulnerabilidade infanto-juvenil, se coloca latente um tratamento normativo diverso, que tende a uma proteção no sentido relacional (Konder e Teixeira, 2016) contra transgressões aos seus direitos. 
Daí a justificativa da especial proteção da criança e do adolescente e de seus especiais direitos fundamentais e de personalidade, exatamente porque estas pessoas se encontram em um estágio da vida que carecem de autonomia, liberdade e plena capacidade de se autodeterminar, necessitando que seus pais supram de forma material e imaterial suas necessidades e concretizem seus direitos. "Considerando a condição peculiar da criança e do adolescente como pessoas em desenvolvimento, o direito à convivência familiar ganha ainda mais relevância, pois a família é o locus privilegiado para a formação da pessoa humana". (Angelini Neta, 2016: 169).

O Direito de Família, que regula os direitos voltados para as relações parentais e filiais, encontra-se em constante movimento e evolução. Todos os aspectos do relacionamento humano, sejam familiares ou sociais, influenciam na criação do direito e, na mesma proporção, o direito criado influencia diretamente no modo de vida das pessoas. "Sob esse mesmo diapasão, é evidente que o direito que emana da sociedade para a sociedade acompanha os fatos, devendo cumprir com as demandas criadas pela sociedade à qual foi criado". (Scherbaum, Rocha, 2018: 18).

E é exatamente neste contexto é que se volta esta pesquisa para os atuais direitos fundamentais da criança e do adolescente e os direitos fundamentais dos genitores, pois os princípios e as normas constitucionais possuem força normativa imediata, sendo fonte primária do direito, todavia, é preciso compreender os limites dos direitos em face de outros.

\section{LIMITE DOS LIMITES E A FLEXIBILIZACÃO DOS DIREITOS/ PRINCÍPIOS FUNDAMENTAIS DA PERSONALIDADE}

No tocante aos direitos e princípios fundamentais, estes ostentam diversas características, sendo uma delas a de serem estritamente necessários para cada pessoa, de forma particularizada e coletiva. Os direitos fundamentais da personalidade nem sempre constam de forma explícita na legislação, contudo, possuem fundamento constitucional, mesmo que implícito, visto que são extraídos da mesma gênese, que é o princípio da dignidade da pessoa humana.
Este princípio sustenta toda a ordem jurídica da contemporaneidade, tanto no âmbito nacional como no internacional, conferindo legitimidade a todos os outros direitos e funcionando exatamente como o limite dos direitos e limite dos limites. Desta forma, é a "barreira última contra a atividade restritiva dos direitos fundamentais" (Sarlet, 2006: 124).

Logo, é equivocado dizer que os direitos fundamentais e de personalidade são direitos absolutos, no sentido de ser ilimitado em seu exercício pelo titular. Assim, os direitos em tela não são garantidos de forma absoluta, pois quando estão em situação de conflito, um pode ceder ao outro, e vice-versa, exatamente para a preservação de uma eficácia mínima de todos os direitos (Fachin, 2006). "O caráter absoluto não pode ser compreendido como gerador de imposição ilimitada e em qualquer circunstância. $\mathrm{Na}$ perspectiva relacional, do ser com os outros, o caráter absoluto dos direitos de personalidade se relativiza" (Cantali, 2009: 136).

Para Moraes (2019) os direitos e garantias previstos na Constituição Federal de 1988 não devem ser considerados ilimitados em seu exercício e efetivação, vez que possuem limite exatamente nos demais direitos de igual forma proclamados pelo constituinte. Diante disso, tornou-se pacífica a ideia de que "os direitos fundamentais podem sofrer limitações quando enfrentam outros valores de ordem constitucional, inclusive outros direitos fundamentais". (Mendes e Branco, 2015: 143).

No âmbito internacional, a Convenção de Direitos Civis e Políticos, de 1966, da Organização das Nações Unidas (ONU), prevê de forma clara limitações de direito "que sejam necessárias para proteger a segurança, a ordem, a saúde, a moral pública ou os direitos e liberdades fundamentais de outros". Todavia, é importante frisar que os direitos de cunho constitucional podem apenas sofrer restrições em face de direitos de mesma natureza (Alves, 2010), sejam eles explícitos ou implícitos.

A colisão/conflito tem o condão de relativizar os direitos fundamentais, "mesmo que alguns se aproximem de um caráter absoluto, como o direito à vida" (Cantali, 2009: 137), que é relativizado pela própria Constituição Federal brasileira, que permite a pena de morte em caso 
de guerra declarada (art. 5o, inciso XLVII, alínea “a”, da CF/88) (Brasil, 1988).

Assim, os direitos fundamentais, apesar de sua importância para o Estado Democrático e, principalmente, para as pessoas, não são absolutos (Fachin e Vince, 2017). Esta relativização ocorre exatamente pelo fato de que o Direito encontra a sua sustentação nas próprias pessoas. "Não fosse para regular a vida em sociedade, o Direito sequer teria sentido. Assim, nesta perspectiva intersubjetiva e relacional do ser com o outro, resta clarividente a possibilidade de restrição de direitos" (Cantali, 2009: 138).

Quando se fala em limitação de direitos tão relevantes para o desenvolvimento da pessoa, bem como para a realização de uma vida digna, o estudo se volta para o núcleo de cada direito tutelado pela ordem jurídica, e esse núcleo pode ser traduzido como "o conteúdo mínimo e intangível do direito fundamental, que deve sempre ser protegido em quaisquer circunstâncias, sob pena de fulminar o próprio direito" (Alves, 2010: 40).

A teoria da essência do direito fundamental se divide em absoluta e relativa. A vertente absoluta defende que o núcleo essencial da norma (wesensgehalt) é extraído de forma abstrata, não sendo influenciado pelas circunstâncias fáticas. Já a corrente relativa, compreende este núcleo como algo que somente pode ser extraído ao se observar uma situação em concreto, ou seja, sofrerá mutação dependendo do conflito e do caso fático (Mendes e Branco, 2017).

Este núcleo essencial, que tende a se preservar, limitará a possibilidade de limitar, isto é, fixa um limite, que não poderá ser ultrapassado pela atividade limitadora dos direitos fundamentais. Portanto, baliza tanto atos legislativos como judiciários frente à limitação de certo direito individual, evitando-se o esvaziamento do direito sucumbente, como forma de impossibilitar a restrição descabida, desmesurada ou desproporcional.

Salvaguardar o núcleo essencial dos direitos fundamentais da personalidade é legitimar a decisão proferida entre a colisão de direitos fundamentais e/ou princípios constitucionais, pois quando estes não são respeitados, eliminase um deles, retirando a sua substância elementar
(Zavascki, 1996) e maculando a decisão em seu conteúdo.

Dessa forma, Fachin e Vince, 2017, entendem que o mecanismo de ponderação e o princípio da proporcionalidade atuam exatamente para efetivar e preservar o núcleo essencial, impondo um limite aos limites para "a legitimidade e adequação das normas com os ditames da justiça e da razão. Todavia, o exercício do referido método interpretativo não pode ser realizado de forma crua, pouco elaborada e com base em critérios objetivos" (p.144-145).

O limite dos limites será respeitado quando o juízo de ponderação for exercido conjuntamente com o princípio da proporcionalidade, pois é preciso entender que o sacrifício de um direito só será “justo" quando for necessário, adequado e comedido para a solução do problema, e que não tenha outra saída menos danosa para se chegar ao resultado almejado, ou seja, que a privação não seja maior do que o benefício que se intenta alcançar (Mendes, Branco, 2017). Diante disso, deve o julgador, em caso de colisão, analisar e decidir "qual princípio deve ceder ao outro, de modo que se alcance e se garanta, de forma indubitável, a dignidade da pessoa humana" (Pereira, 2012: 57).

Neste ponto, Barroso (1996: 200) entende que "somente presentes essas condições poder-se-á admitir a limitação a algum direito individual". Produz-se, assim, não uma decisão injusta ou equivocada, mas algo que seja socialmente desejável, compreensível no tempo em que se configure e tenha sacrificado o mínimo possível de cada um dos direitos em oposição. "Por fim, cabe ao intérprete analisar em que medida a decisão a ser tomada para destrinçar a colisão de direitos fundamentais atende ao princípio fundamental da dignidade da pessoa humana" (Bessa, 2006: 18). A dignidade da pessoa humana deve sempre ser o cerne para a ponderação.

Com efeito, não se pode dizer de imediato, e sem um caso em concreto, que um direito prevalecerá sobre outro e, mesmo que se entenda que os direitos fundamentais necessitam de sua concretização de forma mais ampla, é preciso também compreender que a partir do momento em que cada pessoa vive e convive em sociedade, seus direitos fundamentais e de personalidade sofrerão certas restrições, maiores ou menores, 
dependendo do caso, uma vez que dificilmente um direito será exercício ilimitadamente sem que atinja outrem.

Os direitos fundamentais em foco nesta pesquisa não devem ser analisados de forma isolada, mas sim em harmonia com todo o ordenamento jurídico brasileiro, entendendo-se o Direito como base de um sistema unitário depois da constitucionalização do Direito Civil (Siqueira, Oliveira, Zanini e Franco Jr.,2018), principalmente do Direito de Família.

A constitucionalização do Direito de Família é algo inegável, e que acarretou mudanças não apenas nas relações conjugais, mas principalmente nas parentais e filiais, atribuindo à criança e ao adolescente especial e absoluta prioridade no grupo familiar. A constitucionalização "foi essencial para o processo de humanização das relações familiares e à derrocada da estrutura patriarcal então vigente" (Scherbaum e Rocha, 2018: 19).

Mudaram-se os paradigmas e as antigas concepções no que tange à responsabilidade $\mathrm{e}$ aos deveres parentais, bem como às necessidades e aos direitos do filho, fato que fez surgir não apenas colisões de direitos, mas uma necessidade de hermenêutica jurídica em face destas relações.

\section{DA COLISÃO DOS DIREITOS FUNDAMENTAIS E A APLICAÇÃO DA TÉCNICA DE PONDERACC̃̃O E DO PRINCÍPIO DA PROPORCIONALIDADE}

Os direitos fundamentais e os princípios constitucionais exercem grande função hermenêutica em face da aplicação e da compreensão dos ditames da Constituição Federal de 1988 e, diferentemente das regras/ leis, os princípios podem ser compreendidos como "mandadosprima facie e não definitivos, ao passo que as regras são mandados que se aplicam ou não" (Pereira, 2012: 55). E, por este motivo, a forma de analisá-los e aplicá-los à situação fática é sempre diversa.

Os direitos dessa natureza vão muito além de normas pilares de outras, eles, em verdade, são normas que harmonizam toda a sociedade e suas relações jurídicas (Miranda, Branco, Branco, 2017). Assim, tanto os direitos como os princípios fundamentais se resumem em "uma concepção do mundo que orienta e informa a luta popular para a conquista definitiva da efetividade desses direitos" (Silva, 2005: 179).

E é exatamente neste ambiente social que ocorrem as principais violações de direitos fundamentais e o desrespeito aos princípios constitucionais, em razão de que nas relações entre particulares os envolvidos geralmente possuem os mesmos direitos. Para proteger uma pessoa de outra mais poderosa, ou em situação privilegiada, como é o caso dos filhos em face de seus pais, a teoria da eficácia horizontal estende os valores constitucionais protetivos para além do Estado, de forma a englobar as relações privadas $\mathrm{e}$, consequentemente, as familiares.

Assim, Alexy formulou uma teoria para a efetivação dos ditames da Constituição em um nível satisfatório, a fim de que esta não se tornasse apenas uma carta de boas intenções. "A teoria dos princípios pode, pelo contrário, levar a sério a Constituição sem exigir o impossível" (1999: 79). Esta teoria declara as normas e/ou princípios que não se cumprem como um todo exatamente em razão da existência de outrem, devendo ponderálos e, desta maneira, ficar sujeitos de certa forma a uma reserva do possível, voltada para o entendimento de que há um limite diante daquilo que a pessoa pode ou não exigir de forma razoável tanto do Estado como de outro particular.

Referida técnica foi tão bem aceita no Brasil que veio a ser incluída expressamente no Código de Processo Civil de 2015, que tratou dos elementos que devem compor uma sentença, estabelecendo, no $\S 2^{\circ}$, do art. 489 , que "no caso de colisão entre normas, o juiz deve justificar o objeto e os critérios gerais da ponderação efetuada, enunciando as razões que autorizam a interferência na norma afastada e as premissas fáticas que fundamentam a conclusão" (Brasil, 2015).

A colisão de direitos fundamentais em sentido estrito ocorre sempre que o exercício ou a realização de um direito acarreta consequências negativas sobre direitos de outra pessoa. Os direitos fundamentais colidentes podem tratarse dos mesmos ou de direitos fundamentais diversos (Alexy, 1999). Desta feita, diante de eventual conflito entre direitos individuais de mesma natureza, importância social e histórica, o mecanismo de ponderação e de proporcionalidade 
possibilita que todos os direitos envolvidos sejam considerados e analisados (Mastrodi, 2014).

Nos ensinamentos de Alexy (1999, p.73), o fenômeno de colisão de direitos fundamentais possibilitou as:

[...] constelações altamente diferentes que, porém, têm algo em comum: todas as colisões podem somente então ser solucionadas se ou de um lado ou de ambos, de alguma maneira. Limitações são efetuadas ou sacrifícios são feitos. A questão é como isso deve ocorrer. Na resposta a esta questão devem ser tomadas decisões fundamentais sobre a estrutura fundamental da dogmática dos direitos fundamentais (Alexy, 1999: 73).

Em caso de colisão entre direitos fundamentais e/ou princípios constitucionais, o que será analisado será o que é o melhor a se decidir naquele momento, e não escolher o que é devido (Cambi, 2011). Assim, em consonância com o princípio da concordância prática, tanto os princípios constitucionais quanto os direitos fundamentais deverão ser harmonizados em face da sociedade, e será "por meio de juízo de ponderação, que vise preservar e concretizar ao máximo os direitos e bens constitucionalmente protegidos" (Farias, 1996: 98), que ocorrerá essa adequação do texto constitucional à realidade fática.

Quando existe a necessidade de sopesamento, é necessário que se evidencie que "não se está diante de valores aritméticos, motivo pelo qual a equação do problema não se resolve por métodos matemáticos" (Fachin e Vince, 2017: 137), mas sim pautado em ponderação e na proporcionalidade, fazendo-se uma análise crível para que se chegue a uma decisão muito mais do que adequada, mas justa ao caso concreto.

Logo, compreende-se que não existe hierarquia entre os elementos fundamentais constitucionais (Mendes, Branco, 2017), mas quando se está diante de um conflito entre estes, será necessário impor um "peso abstrato", a fim de se buscar uma concordância prática, pois, diferentemente da teoria, no caso concreto haverá uma limitação de um em benefício do outro (Zavascki, 1996). "Isso é o quase se quer dizer quando se afirma que, no caso concreto, os princípios têm pesos diferentes e que os princípios com o maior peso têm precedência" (Alexy, 2015: 93-94). A decisão que colocará fim à colisão deve se fundamentar em todo o ordenamento jurídico, não sendo regida apenas por um raciocínio lógico-formal, mas sim por uma verdadeira ponderação valorativa (Negreiros, 2001).

Esta técnica jurídica, denominada de ponderação, e também chamada pela doutrina norte-americana de balancing, é utilizada para solucionar eventuais conflitos normativos e principiológicos que não podem ser superados com as tradicionais formas hermenêuticas de resolução (Barcellos, 2005). Pontua-se, ainda, que esta técnica somente pode ser utilizada em face de casos concretos, e não meramente hipotéticos (Mendes, Branco, 2015).

Nessa perspectiva, é que se colocam em pauta as relações familiares entre pais e filhos e, mesmo que o princípio da intervenção mínima paire sobre estas relações, "o setor privado não é inviolável, e não pode ficar imune aos preceitos instalados na Lei Maior" (Fachin e Vince, 2017: 73).

No âmbito parental, existe "igualdade" de condições, pois tanto os genitores como os filhos são detentores dos mesmos direitos fundamentais. "Haverá de se proceder uma ponderação entre os valores envolvidos, com vistas a alcançar uma harmonização entre eles no caso concreto (concordância prática)" (Mendes e Branco, 2015: 177). Nestes conflitos familiares não se pode pensar na eliminação por completo de um direito fundamental em face de outro (Sarlet, 1998), já que o que se deve ter em mente é que é preciso ter uma equalização, harmonia não apenas para a resolução do conflito, mas para a proteção da criança e do adolescente e de seus genitores.

A convivência entre os membros familiares é de extrema importância para o desenvolvimento tanto dos filhos como de seus pais, pois é nesta troca de afeto e cuidado é que os laços se fortalecerão e prosperarão. "A finalidade do instituto é a de permitir a manutenção de uma natural e adequada comunicação do filho com o genitor com quem não convive, para estimular e reforçar a parentalidade, permitindo o sadio e regular desenvolvimento do menor". (Gama, 2001: 171).

Por este motivo é que a Constituição impôs de forma expressa e clara o dever da família de garantir à criança e ao adolescente, com 
extrema prioridade, "condições plenas para o seu desenvolvimento, através da garantia de alguns direitos fundamentais, dentre os quais, o direito à convivência familiar" (Angelini Neta, 2016: 166).

E a técnica da ponderação visa exatamente preservar os direitos tanto parentais como filiais, não podendo ser reduzida a uma maneira de aplicar princípios, uma vez que "trata-se na verdade de uma técnica de decisão autônoma que, embora muitas vezes envolva princípios, não se vincula a eles de maneira exclusiva" (Barcellos, 2005: 36), mas sim, de forma complementar, a toda ordem normativa, a fim de se alcançar a justiça social e a máxima efetivação dos preceitos constitucionais.

0 processo de ponderação (balancing process) não atribui exatamente uma compreensão sobre o texto constitucional, mas equilibra e coordena os bens conflitantes ou, ao menos, tenta reduzir a tensão entre eles no caso concreto. 0 objetivo da ponderação é a solução destes conflitos de forma menos traumática, isto é, chegar a uma solução onde as normas em oposição continuem a coexistir, mas "sem a negação de qualquer delas, ainda que em determinado caso concreto elas possam ser aplicadas em intensidades diferentes" (Barcellos, 2003: 57).

Neste mesmo sentido, Mastrodi (2014, p.581) entende que quando se está diante de uma colisão entre princípios ou entre direitos fundamentais de igual dignidade constitucional "fica impensável imaginar a eliminação de um princípio em detrimento do outro, pois ambos os princípios devem permanecer, ainda que um prevaleça sobre o outro".

A técnica de ponderação se aloca no princípio da proporcionalidade, que pode ser mais bem entendido sob a análise dos seus três níveis, que a doutrina majoritária denomina de subprincípios, sendo eles: o da adequação, da necessidade e da proporcionalidade em sentido estrito:

[...] assim é que dele se extraem os requisitos (a) da adequação, que exige que as medidas adotadas pelo Poder Público se mostre aptas a atingir os objetivos pretendidos; (b) da necessidade ou exigibilidade, que impõe a verificação da inexistência de meio menos gravoso para atingimento dos fins visados; e (c) da proporcionalidade em sentido estrito, que é a ponderação entre ônus imposto e o benefício trazido, para constatar se é justificável a interferência na esfera dos direitos cidadãos (Barroso, 1996: 209).

Neste viés, o princípio da proporcionalidade chama para si a importante função de nortear as soluções que o julgador deverá tomar, "tendo em vista que concilia dois valores primordiais" (Alves, 2010: 34). É preciso compreender que a relação familiar é um contexto particularizado, que deve receber especial atenção, seja do Executivo, Legislativo ou Judiciário, exatamente pelo fato de que é na família que se desenvolve a criança e o adolescente, pessoas vulneráveis, não podendo mais subsistira antiga concepção de que estes estão subjugados às vontades e aos caprichos de seus genitores, e que devem ser submissos ou que não possuem direitos.

Portanto, o equilíbrio entre os direitos fundamentais dos pais e dos filhos é imprescindível, ainda mais no que se refere à convivência familiar, importante direito que visa não apenas o convívio físico, mas o desenvolvimento psicoemocional do menor.

\section{DO DIREITO À LIBERDADE INDIVIDUAL DO GENITOR EM FACE DO DIREITO À CONVIVÊNCIA FAMILIAR DO FILHO}

Embora a atual Constituição brasileira não tenha colocado de forma expressa privilégios a alguns direitos em face de outros, o interesse da criança e do adolescente se mostra em voga no diploma legal, que demonstra extrema preocupação com o desenvolvimento e proteção destes. Por esta justificativa é que não paira dúvida de que estas pessoas em desenvolvimento gozam de especial tutela constitucional, bem como que todos os seus direitos se encontram vinculados ao princípio da dignidade da pessoa humana (Cardin, Mochi, 2018). "Logo, devem ser levados em conta, em eventual juízo de ponderação, os valores que constituem inequívoca expressão desse princípio". (Alves, 2010: 30).

No que tange à convivência familiar, os seus fundamentos, como o direito da criança e do adolescente, bem como um direito-dever dos genitores, se encontram expressos no texto constitucional $^{4}$ e, ainda, previstos na legislação

4. Art. 227, CF/88: É dever da família, da sociedade e do Estado assegurar à criança, ao adolescente e ao jovem, com absoluta 
infraconstitucional (Lei no 8.069/90 - Estatuto da Criança e do Adolescente (ECA) ${ }^{5}$, Código Civil $^{6}$ e Convenção dos Direitos da Criança ${ }^{7}$ ).

Alguns autores tratam este direito também como um princípio regente do Direito de Família. É o caso de Lôbo (2008: 53), que preceitua que "viola esse princípio constitucional a decisão judicial que estabelece limitações desarrazoadas ao direito de visita do pai não guardião do filho, pois este é o titular de direito próprio à convivência familiar com ambos os pais", justificando-se essa configuração principiológica exatamente porque a simples assistência material e educacional não é suficiente para os menores, em outras palavras, "é preciso garantir a convivência dos filhos com os pais", já que esta é "fundamental para a formação da personalidade do indivíduo" (Angelini Neta, 2016: 85).

Em contraponto a este ditame, voltadas para a proteção da criança e do adolescente e para a manutenção da unidade familiar é que se encontram a liberdade individual e a autonomia da vontade dos genitores que, de forma corriqueira na sociedade brasileira, têm se pautado nestes direitos para o não cumprimento de suas responsabilidades parentais no que se refere à convivência familiar, fato que gera inúmeras ações de indenização por abandono afetivo.

Por isso, se faz necessária a análise destes direitos sob a perspectiva da ponderação e da proporcionalidade. A primeira etapa da ponderação consiste em definir quais são os

prioridade, o direito à vida, à saúde, à alimentação, à educação, ao lazer, à profissionalização, à cultura, à dignidade, ao respeito, à liberdade e à convivência familiar e comunitária, além de colocá-los a salvo de toda forma de negligência, discriminação, exploração, violência, crueldade e opressão. (Brasil, 1988).

5. Art. 19, ECA: É direito da criança e do adolescente ser criado e educado no seio de sua família e, excepcionalmente, em família substituta, assegurada a convivência familiar e comunitária, em ambiente que garanta seu desenvolvimento integral. (Brasil, 1990).

6. Art. 1.632, CC: A separação judicial, o divórcio e a dissolução da união estável não alteram as relações entre pais e filhos senão quanto ao direito, que aos primeiros cabe, de terem em sua companhia os segundos. (Brasil, 2002).

7. Artigo 9. 3, da Convenção dos Direitos da Criança: Os Estados Partes respeitarão o direito da criança que esteja separada de um ou de ambos os pais de manter regularmente relações pessoais e contato direto com ambos, a menos que isso seja contrário ao interesse maior da criança. (ONU, 1989). direitos fundamentais que estão em conflito. Em seguida, na segunda etapa, é preciso examinar as circunstâncias fáticas e as suas consequências jurídicas e sociais, "daí se dizer que a ponderação depende substancialmente do caso concreto e de suas particularidades" (Barcellos, 2005: 93).

Ao realizar esse exame de valores e preponderância, o Judiciário, de forma inequívoca, ao se deparar com o caso concreto, terá de "descumprir" uma norma constitucional, sacrificando um direito fundamental em detrimento de outrem. "O julgador deverá decidir qual norma 'vale menos', e essa restrição somente poderá ser admitida de for proporcional” (Fachin e Vince, 2017: 142).

Tanto a liberdade individual (art. 5으, caput, CF/88) como a convivência familiar (art. 227, caput, CF/88) são direitos fundamentais e, de igual forma, considerados princípios constitucionais tanto pela doutrina como pela jurisprudência. Sendo que o direito à liberdade individual do genitor não guardião se traduz como "direito de cada um de se manifestar consoante a sua vontade, excluída, porém, aquela esfera de atividade realmente indiferente ao ordenamento jurídico" (Cupis, 2004: 108). 0 direito à convivência familiar pode ser compreendido como "um dever e direito de uma fluída comunicação, em contínua correspondência com o filho e seu ascendente não guardião, imiscuindo-se na educação e formação do filho e das atividades usuais e correntes da vida do rebento" (Madaleno, 2019: 477).

Posto isso, há de se indagar se todos os direitos constitucionais individuais e coletivos

[...] são dotados de igual validade, sendo formalmente iguais, o que confere prevalência de um sobre o outro em qualquer situação concreta, o que dá a cada direito força normativa maior ou menor em relação aos demais direitos não está dentro do direito, mas fora dele (Mastrodi, 2014: 589).

É exatamente isso, o que está fora destas previsões legais, que determinará o deslinde desta colisão: será a situação fática, as peculiaridades do caso, os valores sociais e a compreensão de mundo dos envolvidos os elementos que ditarão a solução do conflito. Deve-se, desse modo, ponderar os direitos que estão em análise, "atribuindo-lhes pesos, de modo a encontrar o conteúdo e o grau de 
aplicabilidade de cada princípio no caso concreto" (Pereira, 2012: 55).

Todavia, diferentemente das situações em que realmente existe uma colisão entre iguais direitos ou de direitos diferentes, mas de mesma natureza, também existem "situações que podem ludibriar o intérprete à primeira vista. Com efeito, uma interpretação meramente literal da norma de direito fundamental pode fazer crer protegida certa situação, que na verdade foge ao real âmbito de proteção deste direito" (Bessa, 2006: 3).

Estabelecer qual é o verdadeiro âmbito de proteção e de atuação dos direitos fundamentais é algo complicado, inicialmente porque referidos direitos apresentam-se e se perfazem de inúmeras formas, tanto na relação da pessoa consigo mesma como com outras pessoas, além de que possuem um conteúdo aberto a inúmeras interpretações. Mendes estabelece que:

Não raro, a definição do âmbito de proteção de determinado direito depende de uma interpretação sistemática, abrangente de outros direitos e disposições constitucionais. Muitas vezes, a definição do âmbito de proteção somente há de ser obtida em conflito com eventual restrição a esse direito (2002: 212).

Conforme a teoria dos valores, a positivação dos direitos fundamentais tende à realização dos valores tutelados pela Constituição brasileira. Necessitando-se, ainda, que se verifique a finalidade/função social do direito constitucionalmente previsto, isto é, o âmago de tutela protegerá o indivíduo até o limite da função social do direito fundamental, ou seja, a pessoa terá o seu direito assegurado quando o seu exercício não fugir do contexto de proteção (Bessa, 2006).

É relevante trazer em pauta a proteção dos direitos fundamentais pelo fato de que certas situações, que inicialmente caracterizam um conflito, em verdade não o são. Como se pode observar na problemática em comento, o que ocorre é uma simples mensuração equivocada do âmbito de proteção do direito à liberdade individual do genitor não guardião. Tal fato é chamado de colisão aparente, já que não ocorre realmente uma colisão com o direito à convivência familiar do filho, mas sim uma simples aparência de conflito, que pode ser solucionado com a identificação e a fixação dos âmagos de proteção dos direitos fundamentais em análise.

A afirmativa acima se sustenta em várias concepções sociais e legais, inicialmente porque os "direitos e deveres referentes à sociedade conjugal são exercidos igualmente pelo homem e pela mulher, especialmente aqui o direito de igualdade entre ambos, já consignado no art. 5o, I (art. 226)" (Silva, 2005: 848). Assim, é incompreensível que os cuidados imateriais sejam dados somente por um dos genitores, aquele que detém a guarda física, pelo simples fato de um deles não querer cumprir seus deveres parentais.

Seguindo este entendimento, a proteção da criança se perfaz desde a concepção constitucional à infraconstitucional, como se extrai do art. 3.․․, do Estatuto da Criança e do Adolescente (ECA), que determina a proteção integral, bem como a previsão do princípio do melhor interesse da criança (the best interest of the child), nos termos previsto na Convenção Internacional de Haia, que abarca a proteção dos interesses dos menores (Tartuce, 2019).

Assim, Cardin e Mochi entendem que:

A vulnerabilidade da criança e do adolescente, seja no aspecto físico psicológico ou mesmo sexual, evidencia a necessidade de receberem a proteção especial que lhes assegurada nos tratados e convenções internacionais ratificados pelo Brasil, bem como pelo ordenamento jurídico brasileiro. A despeito de ser papel do Estado e da sociedade garantir a tutela integral, a família, sobretudo o pai, a mãe ou os responsáveis, desempenham uma função insubstituível no desenvolvimento da personalidade dos filhos (2018, p.55).

Portanto, em nada se altera a relação dos genitores com os filhos diante do fim da conjugalidade ou se encerram as responsabilidades que estes têm em face da prole, uma vez que a unidade familiar se mantém para com o filho, já que "por meio de uma perspectiva psicológica-social, ambas as funções são essenciais na formação da criança" (Fonseca e Carrieri, 2019, p.34).

A liberdade individual foi exercida pelo genitor não guardião no momento da decisão por ter ou não um filho, e no momento em que um novo ser humano é concebido, geram-se deveres, 
obrigações e responsabilidades. Este vínculo parental, seja ele biológico ou socioafetivo, não pode ser rompido por mera liberalidade de uma ou de ambas as partes. Conforme Hironaka:

A relação paterno-filial não é marcada pela transitoriedade - como, de resto, é a característica intrínseca das relações de conjugalidade, entre as quais se incluem tanto as relações derivadas do casamento quanto as derivadas da união estável. 0 fato de ser a relação paterno-filial inamovível e perpétua lhe confere um traço ímpar, distinto de tudo o mais que se queira apreciar, em paralelo ou em comparação, na esfera do Direito de Família, ou no núcleo familiar (Hironaka, 2006: 15).

A ausência injustificada do pai ou da mãe é propulsor evidente de uma dor psíquica que, de forma presumida, provoca prejuízos ao crescimento e ao desenvolvimento da criança, tendo em vista que tal ausência não acarreta somente a falta de afeto, mas também de cuidado e de proteção (Hironaka, 2006). A convivência familiar entre os genitores e sua prole objetiva exatamente preservar a higidez física e mental dos filhos, garantindo-lhes o cuidado e a assistência material e moral. "Significa, pois, ser pai e/ou mãe, no profundo sentido dessas palavras". (Angelini Neta, 2016: 167).

Esta imposição legal de convívio se verifica com inúmeros julgados de procedência em face da reparação civil por abandono afetivo, sendo os pais responsáveis diretos pelo desenvolvimento bio-psico-socio-cultural das crianças e dos adolescentes (Fonseca e Carrieri, 2019).

0 que demonstra que o âmbito de proteção do direito à liberdade individual não abarca esta decisão parental individualista em face da convivência familiar, exatamente pelo motivo de que o vínculo parental limitará, consequentemente, a liberdade dos genitores para o cumprimento e a efetivação dos direitos fundamentais da personalidade dos filhos, possibilitando a estes um respaldo material e imaterial para o desenvolvimento pessoal. Como pontua Nicolau Júnior é importante observar que as crianças reconhecidas como filhos "não têm culpa das desídias e dos impulsos dos seus pais e não podem, por isso, sofrer descriminação e repulsa dos seus parentes mais próximos" (Nicolau Junior, 2011: 207).
Pelo contrário, o instituto da autoridade parental impõe exatamente os deveres aos pais de criar, assistir e educar os filhos menores e visa garantir a efetividade de seus direitos fundamentais (Konder, Texeira, 2016), não podendo os genitores se eximirem de tal responsabilidade somente pelo fato de não quererem exercê-la.

0 direito fundamental à liberdade individual, bem como todas as suas ramificações jurídicas, se assenta no ordenamento jurídico e, por este motivo, está sujeito a todos os outros valores, princípios, normas e regras como um todo. A liberdade abstrata, que foi declarada como um direito humano autoevidente (Hunt, 2009), não é um direito imune a limitações, como qualquer outro, independentemente de sua categorização normativa.

Enfim, o melhor interesse da criança e do adolescente, bem como o seu direito de convivência precisa ser efetivado de fato na realidade brasileira, à medida que, sem ele, a vida digna não se realizará e, consequentemente, os direitos da personalidade do filho restarão lesionados.

\section{CONCLUSÕES}

A Constituição Federal de 1988 estipulou no Brasil numerosos direitos fundamentais individuais e sociais, que foram positivados exatamente por uma pressão internacional para se declarar direitos que, mesmo que não cumpridos em sua integralidade, não seriam simplesmente não-vinculativos. Assim, os direitos fundamentais detêm hoje uma força vinculativa jurídica ampla, em forma de justiciabilidade.

Como consequência natural deste contexto, alguns direitos, em certos momentos, entram em conflito com outros direitos, posto que as pessoas são detentoras das mesmas garantias. Logo, nos conflitos, o que se busca é a conciliação entre os bens jurídicos tutelados, aplicando-os cada qual em extensões variadas, a depender do caso.

Além disso, há de se notar que, independentemente do resultado prático, o conflito entre direitos fundamentais ou princípios constitucionais não será resolvido por "nocaute", mas por um sopesamento de ideais, exatamente pelo fato de que estes não seguem a mesma forma 
de resolução dos conflitos que envolvem regras/ leis (tudo ou nada), mas sim a da ponderação.

Assenta-se na doutrina brasileira, e também em sua jurisprudência, a teoria de Robert Alexy, que estipula a ponderação entre princípios, não causando o esvaziamento destes, mas de forma a aplicar a proporcionalidade nas decisões, que prevê que, ao escolher a prevalência de um princípio, deve-se aplicar a decisão menos onerosa possível à parte que teve o seu direto restringido.

Diante do exposto, é possível dizer que tanto os direitos como os princípios não são absolutos, mesmo que a sua gênese esteja vinculada à dignidade humana, de modo que, consequentemente, podem sofrer limitação. É importante dizer que esta restrição ou tolhimento de certa parcela do direito/princípio deve ser adequada, necessária e proporcional, pois só assim será legítima e justa.

Posto isso, verifica-se uma possível situação de "conflito" entre o direito de convivência familiar dos filhos e o direito à liberdade individual dos genitores. Todavia, a compressão de que os menores e seus direitos devem ser tutelados de forma mais abrangente e eficaz já se consolidou no ordenamento jurídico, não só no brasileiro, mas também no contexto internacional.

Restando como sendo uma função precípua dos genitores, a construção e o desenvolvimento pessoal dos filhos, de forma a capacitá-los para que se tornem cidadãos capazes e independentes. Desta maneira, este dever parental de criação e de cuidado para com os filhos menores decorre exatamente dos princípios da parentalidade responsável e da proteção integral do menor, ambos constitucionalmente previstos e que garantem especial prioridade em sua tutela e direitos.
Constatou-se assim, que os deveres e as responsabilidades parentais limitam e restringem certos direitos dos genitores, até mesmo os da personalidade, exatamente pelo fato de que, por livre e espontânea vontade, colocaram no mundo um novo ser. Nesse sentido, entendese que este ato de vontade gera obrigações morais e, principalmente, jurídicas, que acabam por ocasionar uma limitação de certos direitos fundamentais da personalidade, como é o exemplo do direito à liberdade individual em face do direito à convivência familiar, não podendo o genitor não guardião escolher se quer ou não conviver e cuidar de seus filhos, já que cuidado vai muito além de valores pecuniários.

Assim, concebendo o entendimento de que de fato não ocorre uma colisão de direitos fundamentais de personalidade frente à liberdade individual e à convivência familiar, o que verdadeiramente se perfaz é uma colisão aparente. Inicialmente, é possível se pensar que existe uma colisão, mas quando verificado o âmbito de proteção destes direitos, a convivência familiar tem preponderância sobre a liberdade do genitor, exatamente diante do dever de cuidado que existe na relação paterno/materno filial.

Conclui-se então que, as decisões judiciais devem se pautar em todo o sistema normativo e principiológico, bem como na especial proteção da criança e do adolescente em face dos interesses particulares dos genitores. Sendo necessária uma maior sensibilidade por parte dos operadores do direito, para que compreendam toda a problemática que envolve as relações familiares. Defende-se assim, que não existem direitos a serem ponderados, exatamente pelo fato de que a convivência familiar é um direito fundamental da criança e dever jurídico dos genitores, não podendo estes se absterem do dever de cuidado e proteção. 


\section{REFERENCIAS BIBLIOGRÁFICAS}

- Alexy, R. (1999). Colisão de direito fundamentais e realização de direitos fundamentais no Estado de Direito democrático. Revista de direito Administrativo, 217, 67-79.

- ------. (2009). Conceito e validade do direito. São Paulo: WMF Martins Fontes.

- ------. (2015). Teoria dos direitos fundamentais. São Paulo: Malheiros.

- Alves, N. C. (2010).Colisão de direitos fundamentais e ponderação. Meritum, 5(1), 25-48.

- Angelini Neta, A. H. (2016). Convivência parental e responsabilidade civil: indenização por abandono afetivo. Curitiba: Juruá.

- Anjos Filho, R. N. (2013). Direito ao desenvolvimento. São Paulo: Saraiva.

- Ávila, H. (2005). Teoria dos princípios jurídicos: da definição à aplicação dos princípios jurídicos. São Paulo: Malheiros.

- Barcellos, A. P. de. (2003). Alguns Parâmetros Normativos para a Ponderação Constitucional. In: Barroso, L. R.(ed.).A Nova Interpretação Constitucional: ponderação, direitos fundamentais e relações privadas. (pp. 49-118). Rio de Janeiro: Renovar.

- ------. (2005).Ponderação, racionalidade $e$ atividade jurisdicional. Rio de Janeiro: Renovar.

- Barroso, L. R. (1996). Interpretação e aplicação da Constituição: fundamentos de uma dogmática constitucional transformadora. São Paulo: Saraiva.

- Bessa, L. S. (2006). Colisões de direitos fundamentais: propostas de solução. Inteligência jurídica. Anais do XIV Encontro Nacional do CONPEDI, Fortaleza, 2006, 1-20.

- Brasil. (1988). Constituição da República Federativa do Brasil de 1988. Brasília,
Diário Oficial da União, Seção 191-A, 5 dez. 1988, p.1.

- ---.-. (1990). Lei $n^{-}$8.069, de 13 de julho de 1990. Dispõe sobre o Estatuto da Criança e do Adolescente e dá outras providências. Brasília, Diário Oficial da União, 16 jul. 1990, p.13563.

- -----. (2002). Lei no 10.406, de 10 de janeiro de 2002. Institui o Código Civil. Brasília, Diário Oficial da União, 11 jan. 2002, p.1.

- ----. (2015). Lei no 13.105, de 16 de março de 2015. Código de Processo Civil. Brasília, Diário Oficial da União, 17 mar. 2015, p. 1.

- Cambi, E. (2016). Neoconstitucionalismo e neoprocessualismo: direitos fundamentais, políticas públicas e protagonismo judiciário. São Paulo: Almedina.

- Cantali, F. (2009). Direitos de personalidade: disponibilidade relativa, autonomia privada e dignidade humana. Porto Alegre.

- Cardin, V. S. G. e Mochi, T. de F. (2018). Crianças e adolescentes vítimas de violência familiar. Brasília: Zakarewicz.

- Cupis, A. de. (2004). Os direitos da personalidade. Campinas: Romana Jurídica.

- Fachin, L. E. (2006). Direitos da Personalidade no Código Civil Brasileiro: elementos para uma análise de índole constitucional da transmissibilidade. Revista Jurídica: órgão nacional de doutrina, jurisprudência, legislação $e$ crítica judiciária, 55, 43-60.

- Fachin, Z. e Vince, F. (2017). Aplicação dos direitos fundamentais nas relações particulares: uma análise com base na doutrina nacional e jurisprudência atual do Supremo Tribunal Federal. Toledo: Vivens. 
- Farias, E. P. (1996). Colisão de Direitos: a honra, a intimidade, a vida privada e a imagem versus liberdade de expressão $e$ informação. Porto Alegre: Fabris.

- Fermentão, C. A. (2006). Os direitos da personalidade como direitos essenciais e a subjetividade do direito. Revista Jurídica Cesumar, 6 (1), 241-266.

- França, R. L. (1996). Instituições de direito civil. São Paulo: Saraiva.

- ------. (1999). Instituições de direito civil. São Paulo: Saraiva.

- Fonseca, L. e Carrieri, A. de P. (2019). O abandono afetivo deve ser indenizado? Reflexões jurídicas, psicológicas e sociais. Revista Direito e Justiça: Reflexões Sociojurídicas, 19 (35), 13-40.

- Gagliano, P. e Pamplona Filho, R. (2003). Novo curso de direito civil. São Paulo: Saraiva.

- Hironaka, G. M. (2006). Os contornos jurídicos da responsabilidade afetiva na relação entre pais e filhos-além da obrigação legal de caráter material. Repertório de Jurisprudência IOB, 3 (18),1-29.

- Gama, G. C. (2001). Direito de família: (Introdução-Abordagem sob a perspectiva civil-constitucional). São Paulo: Juarez de Oliveira.

- Hunt, L. (2009). A invenção dos direitos humanos: uma história. São Paulo: Cia Das Letras.

- Karow, A. B. S. (2012). Abandono afetivo: valorização do afeto nas relações paternofiliais. Curitiba: Juruá.

- MARTins, F. J. B. (2009). Dignidade da pessoa humana- Princípio Constitucional Fundamental. Curitiba: Juruá.

- Mastrodi, J. (2014). Ponderação de direitos e proporcionalidade das decisões judiciais. Revista Direito FGV, 10 (2), 577-596.

- Mendes, G. F. (2002). Os direitos individuais e suas limitações: breves reflexões. In: Mendes, G. F., Coelho, I. M. e Branco, P. G. Hermenêutica Constitucional e Direitos Fundamentais. (pp.197-322). Brasília: Brasília Jurídica.

- Mendes, G. F. e Branco, P. G. (2015). Curso de direito constitucional. São Paulo: Saraiva.

- ------. (2017). Curso de direito constitucional. São Paulo: Saraiva.

- Moraes, A. de. (2019). Direito Constitucional. São Paulo: Atlas.

- Negreiros, T. (2001). A dicotomia público-privado ao problema da colisão de princípios. In: Torres, R. L. Teoria dos direitos fundamentais. Rio de Janeiro: Renovar.

- Nicolau Júnior, M. (2011). Paternidade e coisa julgada. Curitiba: Juruá.

- ORGANIZAÇÃO DAS NAÇÕES UNIDAS (ONU). (1989). Convenção sobre os Direitos das Crianças. Nova Iorque: Assembleia Geral da ONU.

- Konder, C. N. e Teixeira, A. C. B. (2016). Crianças e adolescentes na condição de pacientes médicos: desafios da ponderação entre autonomia e vulnerabilidade. Pensar-Revista de Ciências Jurídicas, 21(1),70-93.

- Pereira, R. da C. (2012). Princípios fundamentais norteadores do direito de família. São Paulo: Saraiva.

- Perlongieri, P. (2002). Perfis de Direito Civil. Rio de Janeiro: Renovar.

- Sanchís, L. P. (1994). Estudios sobre derechos fundamentales. Madrid: Debate.

- Sarlet, I. W. (1998). A eficácia dos direitos fundamentais. Porto Alegre: Livraria do Advogado.

- ------. (2004). Eficácia dos Diretos Fundamentais. Porto Alegre: Livraria do Advogado.

- -----. (2006). Dignidade da pessoa humana e direitos fundamentais na Constituição Federal de 1988. Porto Alegre: Livraria do Advogado. 
- ------. (2010). Constituição, Direito Fundamentais e Direito Privado. Porto Alegre: Livraria do Advogado.

- Sarlet, I. W. e Marioni, L. G. e Mitidiero, D. (2015). Curso de direito constitucional. São Paulo: Saraiva.

- Scherbaum, J. F. e Rocha, L. S. (2018). A constitucionalização no direito de família no sistema jurídico brasileiro. Revista de Constitucionalização do Direito BrasileiroRECONTO,1(1), 1-21.

- Silva, J. A. da. (1992). Curso de direito constitucional positivo. São Paulo: Malheiros.

- -----. (2005). Curso de direito constitucional positivo. São Paulo: Malheiros.

- Siqueira, D. P., Oliveira, E. A. de, Zanini, L. E. de A. e Franco Jr., R. (2018). Os direitos da personalidade em face da dicotomia direito público - direito privado. Revista de Direito Brasileira, 19, 208-220.

- Spengler, F. M. (2004). O Direito de Família de encontro à Constituição. Revista Direito em Debate, 13 (22), 101-122.

- zaniawski, E. (2005). Direitos da personalidade e sua tutela. São Paulo: Editora Revista dos Tribunais.

- Tartuce, F. (2018). Direito Civil v. 1: lei de introdução a parte geral. Rio de Janeiro: Forense.

- ----. (2019). Direito Civil v. 5: direito de família. Rio de Janeiro: Forense.

- Tepedino, G. (2004). A tutela da personalidade no ordenamento civilconstitucional brasileiro. Rio de Janeiro: Renovar.

- Zavascki, T. A. (1996). Antecipação da tutela e colisão de direitos fundamentais: reforma do código de processo civil. São Paulo: Saraiva. 